\title{
The role of individual factors on corona-induced hypochondriasis and job stress: A case study in workplace
}

\author{
Seyed Mahdi Mousavi ${ }^{1}$, Saeid Yazdanirad ${ }^{2}$, Mahsa Jahadi Naeini ${ }^{3}$, Milad Abbasi ${ }^{1}$, Marzieh Sadeghian*4 (D) \\ Received: 26 Jul 2020 \\ Published: 20 Jan 2021
}

\begin{abstract}
Background: Given the importance of maintaining the mental health of workers, the present study was conducted to determine the effect of the individual factors on hypochondriasis and job stress under the corona epidemic condition in a company.

Methods: This cross-sectional study was performed on 275 workers in 2020 in one of the industries in southern Iran. To gather the data, demographic, researcher-made, standard hypochondria, and job stress questionnaires were sent electronically along with a guide and study objectives. The participants completed the questionnaires during 2 weeks and send them electronically to the research team. Finally, data were analyzed using tests of one-way ANOVA and linear regression in SPSS software version 22.

Results: The results showed that the mean score of hypochondriasis in different groups of variables, including age, work experience, use of personal protective equipment, corona experience, and attention to preventive measures was significantly different ( $<<0.05$ ). Based on the results, the mean score of job stress significantly differed in different groups of variables of personal protective equipment use, corona experience, and awareness on corona $(\mathrm{p}<0.05)$. Moreover, based on the regression relationships, hypochondriasis could be predicted by variables of personal protective equipment, corona experience, awareness on corona, and attention to preventive measures; and job stress could be predicted by variables of awareness on corona and attention to preventive measures.
\end{abstract}

Conclusion: Regarding the importance of providing the physical and mental health of employees, the implementation of measures to reduce stress and hypochondriasis of employees, particularly in identified groups, is helpful.

Keywords: Individual factors, COVID-19, Hypochondriasis, Job stress

Conflicts of Interest: None declared

Funding: Ahvaz Jundishapur University of Medical Sciences (grand number: IR.AJUMS.REC.1399.634)

*This work has been published under CC BY-NC-SA 1.0 license.

Copyright $\odot$ Iran University of Medical Sciences

Cite this article as: Mousavi SM, Yazdanirad S, Jahadi Naeini M, Abbasi M, Sadeghian M. The role of individual factors on corona-induced hypochondriasis and job stress: A case study in workplace. Med J Islam Repub Iran. 2021 (20 Jan);35:11. https://doi.org/10.47176/mjiri.35.11

\section{Introduction}

In late December 2019, unusual cases were observed in patients with pneumonia in Wuhan, China, which led to the introduction of a new type of coronavirus. The World Health Organization (WHO) has named this new corona virus as "new corona virus- 2019" and the resulting disease

Corresponding author:Dr Marziyeh Sadeghian, sadeghian-m@ajums.ac.ir

1. Department of Occupational Health Engineering, School of Public Health, Tehran University of Medical Sciences, Tehran, Iran

2. School of Public Health, Shahrekord University of Medical Sciences, Shahrekord, Iran

3. Department of Occupational Health Engineering, School of Public Health, Isfahan University of Medical Sciences, Isfahan, Iran

4. Ahvaz Jundishapur University of Medical Sciences, Ahvaz, Iran as "corona virus disease Covid-19" $(1,2)$. The onset of the disease is accompanied by several symptoms, such as fever, cough, and asthma. In addition, gastrointestinal symptoms, such as diarrhea and nausea, have also been reported. Notably, it was found that the coronavirus is transmitted

$\uparrow$ What is "already known" in this topic:

The Covid-19 epidemic affects the mental health of the people in addition to their physical health. The hypochondriasis and stress caused by corona can be different among different individuals.

\section{$\rightarrow$ What this article adds:}

The results showed that the mean score of hypochondriasis in variables of age, work experience, use of personal protective equipment, corona experience, and attention to preventive measures was significantly different. Also, the mean score of job stress significantly differed in variables of personal protective equipment use, corona experience, and awareness on corona. 
through droplets and close contact (3). The WHO and many countries' governments have taken measures to inhibit the prevalence of Covid-19, including observance of social distance, quarantine, travel restrictions, and preventing social gatherings. In addition to physical effects, this disease has some psychological consequences at the individual, professional, and social levels, such as anxiety, nervous attack, individuals' fear of each other, and stress (4). In this regard, stress is a phenomenon that exists during human life, and the reason for the spread of stress in human societies is the complexity of the social and personal environment as well as the multiple and simultaneous interaction between humans and their surrounding issues. In the psychological sciences, stress is defined as the feeling of psychological stress and tension. Moreover, stress may have an external source or can be caused by an inner sense of individual (5). Degrees of stress can be effective on increasing and improving people's performance; however, high levels of stress have some consequences, such as anxiety, depression, physical and mental disorders, sleep disorders, decreased body resistance, suffering from frequent infections, decreased concentration, and decreased ability of solving problems (6).The prevalence of infectious diseases causes occurring biopsychological problems in the community. However, most of the studies that have been conducted during the Covid-19 epidemic, have only focused on the physical health of individuals, and not much information is currently available on the mental health of individuals during the Covid-19 epidemic (7). Human power is the main asset of organizations and the first and most valuable component of development in any country (8). In addition, stress can affect a person's health by creating dysfunction and can also lead to the reduced productivity by expanding in the organization (9). According to previous studies, job stresses cause a loss in $50 \%$ to $60 \%$ of work days (10). Therefore, paying attention to work environments and examining job stressors and overcoming them are necessary to improve employee performance as well as increasing the efficiency, effectiveness, and ultimately the productivity of the organization. According to a study conducted in 2020 on workers who wanted to return to works during the Covid-19 epidemic, $1.5 \%$ stress was observed (11). However, stress varies from person to person. Also, the results showed a significant relationship between age and work experience with stress (12). Accordingly, in a study by Manshor et al who examined the sources of job stress among Malaysian managers working in multinational companies, a significant relationship was observed between age and stress (13). Moreover, Ofili in a study has acknowledged that increase in the level of education is accompanied with the increase in the support of officials, promoting the job, better understanding of the job, and improving communication, which consequently lead to the increased job confidence and satisfaction and reduced job stress (14). One of the other psychological consequences of epidemic and pandemic diseases is hypochondriasis. Accordingly, hypochondriasis is a mental disorder in which a person believes to have a serious disease despite he/she is physically healthy. Moreover, this misconception to be considered as a disease must be con- tinued for at least 6 months. A person with hypochondriasis, despite observing no problems or illnesses in clinical and laboratory examinations, believes that he/she has a serious disease and is suspected to a physician diagnosis (15). In this regard, the prevalence rate of this disorder is reported about $5.8 \%$ in the whole society (16). Among the consequences of hypochondriasis, sense of vulnerability to disease and injury, high distress and sadness, depression, anxiety, and decreased general activity can also be mentioned (17). In the meantime, individual characteristics play important roles. In addition, age, gender, marital status, and education degree are among the possible factors affecting the incidence of this disorder. A study conducted by Fink et al, also found that the prevalence of this disorder was equal among men and women (18). Moreover, the highest prevalence rate has been reported in people aged between 20 and 30 years (19). Notably, Ellingson et al have reported the highest prevalence of hypochondriasis disorder in the third decade of life (20). In a study by Barsky et al, no association was observed between hypochondriasis and communicational age (19). Also, hypochondriasis and stress caused by corona may be different among different individuals. Given the importance of maintaining mental health, especially in the difficult days of coping with the corona disease, identifying the individual factors that affect industrial environments can be helpful. Thus, the present study was conducted to determine the effect of the individual factors on hypochondriasis and job stress during the corona epidemic in a workplace .Also, the hypothesis of this study was that some individual differences can affect corona-induced hypochondriasis and job stress.

\section{Methods}

A cross-sectional study was performed in one of the industries in southern Iran in 2020. Participants were selected using a simple random sampling method based on inclusion criteria. Inclusion criteria consisted of higher than 1 year of work experience; lack of active corona disease; lack of chronic diseases, such as cancer, diabetes, acquired immune deficiency syndrome (AIDS), cardiovascular diseases, and MS (multiple sclerosis); the lack of mental disorders, the lack of use of mental medication, and the lack of addiction. The exclusion criteria included the lack of willingness to participate in the study, the lack of cooperation to complete the questionnaires, and filling out the questionnaires randomly and improperly. At first, a list of names of people was provided and 500 people were randomly chosen. Then, their medical records were studied and those who did not have the criteria to enter the study were excluded. Finally, 330 people remained in the study. The percentage of answers to the questionnaires was equal to $80 \%$, and a total of 275 people filled out and sent the questionnaire.

\section{Data collection}

Initially, the selected people were contacted by telephone, the steps and aims of the study were described to them, and they were invited to participate in the study. Then, the questionnaires were sent to them via email or another social network software. A phone number was also 
included for contacting the research team as a way to communicate about possible problems when filling out the questionnaires. The participants completed the questionnaires during 2 weeks and sent them electronically. Finally, 275 participants filled out the questionnaires completely.

\section{Tools}

In the present study, several questionnaires were applied to gather data, including demographic questionnaire, researcher-made questionnaire, standard hypochondria questionnaire, and job stress questionnaire.

\section{Demographic questionnaire}

The questionnaire included general information such as age, work history, occupation, work place, education level, and work shift status.

\section{Researcher-made questionnaire}

The questionnaire included general questions about corona protection, which were as follows: (1) How much do you use personal protective equipment (PPE) at work? (answer score: low $=4$, moderate $=3$, high $=2$, and very high $=1$ ); (2) Have you or your family experienced the corona disease? (answer score: yes $=1$; no $=2$ ); (3) How much do you know about the corona disease? (answer score: very low $=1$, low $=2$, moderate $=3$, and high $=4$ ), and (4) How well do you take precautions for the corona disease? (answer score: low $=1$, moderate $=2$, and high $=3$ ). The answers were scored on a Likert scale. To evaluate the validity of the questionnaire, the content validity ratio (CVR) and content validity index (CVI) were calculated based on Lawshe method and Waltz and Basel method, respectively. Also, Cronbach's coefficient alpha $(\alpha)$ of this questionnaire was calculated for examining its reliability. The values of CVR, CVI, and $\alpha$ were equal to $0.78,0.89$, and 0.92 , respectively. Therefore, the validity and reliability of the questionnaire were confirmed.

\section{Standard hypochondria questionnaire}

The hypochondria questionnaire was developed in 1980 by Evans. The questionnaire measures hypochondria by replying to the questions based on the Likert scale. It has 36 questions and based on the obtained score people are categorized into groups of healthy (score, $0-20)$, borderline (2130 ), mild (31-40), moderate (41-60), and severe (above 60) (21). Khani et al evaluated the validity and reliability of the Persian version of this questionnaire with the Cronbach's alpha coefficient reported to be 0.86 (22).

\section{Job stress questionnaire}

The questionnaire includes 60 questions to evaluate 6 dimensions: role workload, role incompetence, role duality, role range, responsibility, and physical environment by 10 phrase questions. Its scoring is based on the 5-point Likert scale: "never = 1", "sometimes = 2", "often = 3", "usually $=4 "$, and "always $=5$ ". The range of total score is between 60 and 300, and higher scores show high stress levels. General stress is categorized into 4 levels: low stress (score 5099), low to moderate stress (100-149), moderate to severe stress (150-199), and severe stress (200-250) (23). Sharifian et al evaluated the validity and reliability of the Persian version of this questionnaire, and its Cronbach's alpha coefficient was calculated to be 0.83 (24).

\section{Data analysis}

Data were entered into SPSS software version 22. Then, the normality of the variables was investigated using the skewness and kurtosis curves. The results revealed that the model variables have a normal distribution. Thus, a Pearson test was applied to investigate the correlation between the variables. The test of one-way ANOVA was also applied to examine the significant level of the mean difference in various groups. Finally, the linear regression test was used to predict the effects of personal factors.

\section{Results}

The mean age and standard deviation of age of the participants were 43.26 and 9.44, respectively. Table 1 presents the statistical distribution of the other individual factors of the participants. According to the obtained information, most of the participants were over 40 years, had more than 20 years of work experience, had high school diploma and less than high school diploma education level, and work shift. The statistical distribution of the variables of hypochondriasis and job stress are shown in Table 2 . The results show that the statistical distribution of the studied variables is normal. The mean prevalence of hypochondriasis and its standard deviation were 33.37 and 14.87 , respectively. Also, the mean total stress score was $47.86 \pm 107.4$.

The results of one-way ANOVA analysis showed that the mean score of hypochondriasis in different groups of variables of age, work experience, use of personal protective equipment, corona experience, and attention to preventive measures was significantly different. Correspondingly, the results of LSD post hoc analysis indicated that people older than 30 years compared to those younger than 30 years, people with more than 20 years of work experience compared to those with less than 20 years of work experience, people with a history of low use of PPE compared to those with a history of moderate and high use of PPE, people with a corona experience compared to those without a corona experience, and people with a low history of attention to preventive measures compared to those with a high history of attention to preventive measures significantly had higher hypochondriasis scores. However, the score of this parameter did not differ significantly with respect to education level, work shift, and awareness of the corona disease. These results are presented in Tables 3 and 4 .

The results of one-way ANOVA analysis showed that the mean score of the job stress significantly differed in different groups of variables of personal protective equipment use, corona experience, and awareness on corona. In this regard, people with the low and moderate history of using PPE compared to those with the high history of using personal protective equipment, people with a corona experience compared to those without a corona experience, and 
The role of Individual Factors on Corona-Induced Hypochondriasis and Job Stress

\begin{tabular}{|c|c|c|c|c|c|}
\hline \multicolumn{2}{|l|}{ Variables } & \multicolumn{2}{|r|}{ Frequency } & \multicolumn{2}{|c|}{ Relative Frequency } \\
\hline \multirow[t]{4}{*}{ Age } & Less than 30 & & 31 & & \\
\hline & 30 to 40 & & 53 & & \\
\hline & 40 to 50 & & 100 & & \\
\hline & More than 50 & & 91 & & \\
\hline \multirow[t]{4}{*}{ Career length } & Less than 10 & & 31 & & \\
\hline & 10 to 20 & & 53 & & \\
\hline & 20 to 30 & & 100 & & \\
\hline & More than 30 & & 91 & & \\
\hline \multirow[t]{3}{*}{ Education level } & Sub diploma & & 104 & & \\
\hline & Diploma & & 94 & & \\
\hline & Associate degree & & 77 & & \\
\hline \multirow[t]{2}{*}{ Shift work } & Yes & & 154 & & \\
\hline & no & & 121 & & \\
\hline \multirow[t]{4}{*}{ Use of PPE } & Low & & 100 & & \\
\hline & Moderate & & 118 & & \\
\hline & High & & 49 & & \\
\hline & Very high & & 8 & & \\
\hline \multirow[t]{2}{*}{ Experience of corona } & yes & & 90 & & \\
\hline & No & & 185 & & \\
\hline \multirow[t]{4}{*}{ Awareness on corona } & Very low & & 75 & & \\
\hline & Low & & 75 & & \\
\hline & Moderate & & 58 & & \\
\hline & high & & 67 & & \\
\hline \multirow[t]{3}{*}{ Attention to preventive measures } & Low & & 66 & & \\
\hline & Moderate & & 142 & & \\
\hline & High & & 67 & & \\
\hline \multicolumn{6}{|c|}{ able 2. The statistical distribution of hypochondriasis and job stress variables } \\
\hline Variables & Range & \multicolumn{2}{|r|}{ Mean } & \multicolumn{2}{|c|}{ Standard Deviation } \\
\hline \multirow{2}{*}{$\begin{array}{l}\text { Hypochondriasis } \\
\text { Job stress }\end{array}$} & $10.00-65.00$ & & 33.75 & & \\
\hline & $50.00-250.00$ & & 107.40 & & \\
\hline & & & & & \\
\hline Variable & & Mean & Standard Deviation & $\mathrm{F}$ & $\mathrm{p}$ \\
\hline Age & Less than 30 & 24.26 & 12.86 & 8.73 & $<0.001$ \\
\hline & 30 to 40 & 37.17 & 15.06 & & \\
\hline & 40 to 50 & 31.37 & 14.15 & & \\
\hline & More than 50 & 37.62 & 14.41 & & \\
\hline Career length & Less than 10 & 32.12 & 15.34 & 3.98 & 0.008 \\
\hline & 10 to 20 & 32.17 & 13.92 & & \\
\hline & 20 to 30 & 37.55 & 14.55 & & \\
\hline & More than 30 & 56.00 & 2.83 & & \\
\hline Education level & Sub diploma & 31.62 & 1.40 & 2.40 & 0.068 \\
\hline & Diploma & 36.44 & 1.57 & & \\
\hline & Associate degree & 32.20 & 2.36 & & \\
\hline Shift work & Yes & 33.19 & 14.57 & 0.50 & 0.484 \\
\hline & No & 34.46 & 15.28 & & \\
\hline Use of PPE & Low & 36.94 & 15.26 & 4.26 & 0.006 \\
\hline & Moderate & 33.15 & 14.30 & & \\
\hline & High & 31.71 & 14.71 & & \\
\hline Experience of corona disease & Yes & 36.86 & 15.31 & 5.93 & 0.016 \\
\hline & No & 32.24 & 14.45 & & \\
\hline Awareness on corona & Very low & 36.21 & 16.62 & 2.21 & 0.087 \\
\hline & Low & 34.98 & 15.04 & & \\
\hline & Moderate & 33.10 & 13.12 & & \\
\hline & High & 30.18 & 13.56 & & \\
\hline Attention to preventive measures & Low & 37.11 & 16.33 & 2.67 & 0.049 \\
\hline & Moderate & 33.35 & 14.78 & & \\
\hline & High & 31.31 & 13.08 & & \\
\hline
\end{tabular}

people with a very low level of awareness on corona compared to those with the low, moderate, and high levels of awareness significantly had higher job stress scores. However, the mean score of this parameter in different groups of variables of age, work experience, level of education, work shift, and attention to preventive measures did not differ significantly. These results are presented in Tables 5 and 6.
The correlation matrix of the studied variables is presented in Table 7. Generally, the results show that all demographic variables except education level and work shift correlated with coronary hypochondriasis. Notably, the highest correlation with this variable was related to work experience. These results also show that the variables of work experience, corona experience, awareness on corona, 
Table 4. The LSD post hoc analysis results of the mean score of hypochondriasis in different groups

\begin{tabular}{|c|c|c|c|c|c|c|}
\hline \multicolumn{2}{|l|}{ Variable } & Group & & Group & Mean Difference & $\mathrm{p}$ \\
\hline \multirow[t]{6}{*}{ Age } & & Less than 30 & & 30 to 40 & -12.91 & $<0.001$ \\
\hline & & & & 40 to 50 & -7.11 & 0.016 \\
\hline & & & & More than 50 & -13.36 & $<0.001$ \\
\hline & & 30 to 40 & & 40 to 50 & 5.80 & 0.017 \\
\hline & & & & More than 50 & -0.45 & 0.857 \\
\hline & & 40 to 50 & & More than 50 & -6.25 & 0.003 \\
\hline \multirow{6}{*}{\multicolumn{2}{|c|}{ Career length }} & Less than 10 & & 10 to 20 & -0.05 & 0.981 \\
\hline & & & & 20 to 30 & -5.43 & 0.015 \\
\hline & & & & More than 30 & -23.88 & 0.023 \\
\hline & & 10 to 20 & & 20 to 30 & -5.38 & 0.020 \\
\hline & & & & More than 30 & -23.83 & 0.023 \\
\hline & & 20 to 30 & & More than 30 & -18.45 & 0.080 \\
\hline \multirow{3}{*}{\multicolumn{2}{|c|}{ Use of PPE }} & Low & & Moderate & 3.79 & 0.049 \\
\hline & & & & High & 5.23 & 0.034 \\
\hline & & Moderate & & High & 1.44 & 0.115 \\
\hline \multirow{4}{*}{\multicolumn{2}{|c|}{$\begin{array}{l}\text { Experience of corona } \\
\text { Attention to preventive measures }\end{array}$}} & Yes & & No & 4.62 & 0.016 \\
\hline & & Low & & Moderate & 3.76 & 0.089 \\
\hline & & & & High & 5.79 & 0.025 \\
\hline & & Moderate & & High & 2.03 & 0.355 \\
\hline \multicolumn{7}{|c|}{ Table 5. Job stress in different groups } \\
\hline \multirow{5}{*}{$\begin{array}{l}\text { Variables } \\
\text { Age }\end{array}$} & & & Mean & Standard deviation & $\mathrm{F}$ & $\mathrm{p}$ \\
\hline & Less than & & 95.39 & 37.31 & 1.78 & 0.152 \\
\hline & 30 to 40 & & 108.70 & 49.61 & & \\
\hline & 40 to 50 & & 103.20 & 51.05 & & \\
\hline & More than & & 115.36 & 45.69 & & \\
\hline \multirow[t]{4}{*}{ Career length } & Less than & & 100.82 & 45.57 & 1.66 & 0.176 \\
\hline & 10 to 20 & & 107.80 & 49.34 & & \\
\hline & 20 to 30 & & 115.79 & 48.86 & & \\
\hline & More than & & 135.00 & 21.21 & & \\
\hline \multirow[t]{3}{*}{ Education level } & Sub diplon & & 101.01 & 46.20 & 1.05 & 0.371 \\
\hline & Diploma & & 112.57 & 50.45 & & \\
\hline & Associate & gree & 110.03 & 48.12 & & \\
\hline \multirow{2}{*}{ Shift work } & Yes & & 107.25 & 45.56 & 0.01 & 0.951 \\
\hline & no & & 107.60 & 50.84 & & \\
\hline \multirow[t]{3}{*}{ Use of PPE } & Low & & 109.47 & 49.72 & 2.57 & 0.049 \\
\hline & Moderate & & 105.97 & 48.56 & & \\
\hline & High & & 99.80 & 37.51 & & \\
\hline \multirow{2}{*}{$\begin{array}{l}\text { Experience of co- } \\
\text { rona }\end{array}$} & Yes & & 123.02 & 55.25 & 14.97 & 0.001 \\
\hline & No & & 99.81 & 41.93 & & \\
\hline \multirow{4}{*}{$\begin{array}{l}\text { Awareness on co- } \\
\text { rona }\end{array}$} & Very low & & 120.79 & 58.08 & 3.19 & 0.024 \\
\hline & Low & & 105.57 & 46.25 & & \\
\hline & Moderate & & 96.52 & 30.09 & & \\
\hline & High & & 103.90 & 47.17 & & \\
\hline \multirow{3}{*}{$\begin{array}{l}\text { Attention to pre- } \\
\text { ventive measures }\end{array}$} & Low & & 118.08 & 47.81 & 2.33 & 0.099 \\
\hline & Moderate & & 105.28 & 48.56 & & \\
\hline & High & & 101.39 & 45.41 & & \\
\hline
\end{tabular}

Table 6. The LSD post hoc analysis results of the mean score of hypochondriasis in different groups

\begin{tabular}{|c|c|c|c|c|}
\hline Variable & Group & Group & Mean difference & $\mathrm{p}$ \\
\hline \multirow[t]{3}{*}{ Use of PPE } & Low & Moderate & 3.50 & 0.214 \\
\hline & & High & 9.67 & 0.041 \\
\hline & Moderate & High & 6.17 & 0.048 \\
\hline Experience of corona & Yes & No & 23.21 & 0.001 \\
\hline \multirow[t]{6}{*}{ Awareness on corona } & Very low & Low & 15.21 & 0.050 \\
\hline & & Moderate & 24.27 & 0.004 \\
\hline & & High & 16.89 & 0.035 \\
\hline & Low & Moderate & 9.06 & 0.275 \\
\hline & & High & 1.68 & 0.833 \\
\hline & Moderate & High & -7.38 & 0.385 \\
\hline
\end{tabular}

and attention to preventive measures had significant correlations with job stress. Also, an experience of corona had the highest correlation with job stress. In addition, the results indicate that corona-induced hypochondriasis had a significant positive relationship with job stress.

A linear regression analysis was used to predict the scores of the variables of hypochondriasis and job stress, based on demographic characteristics, so the following equations were presented:

Hypochondriasis $=44.10+3.51 \mathrm{X} 1-3.94 \mathrm{X} 2-2.10 \mathrm{X} 3$ $-2.61 \mathrm{X} 4$

Job stress $=135.84-5.56 \mathrm{X} 3-7.47 \mathrm{X} 4$

In these equations $\mathrm{X} 1$ is the score of the use of PPE, X2 the score of corona experience, $\mathrm{X} 3$ the score of awareness from corona, and $\mathrm{X} 4$ the score of attention to preventive measures. These scores were obtained by a researcher- 


\begin{tabular}{|c|c|c|c|c|c|c|c|c|c|c|c|}
\hline \multicolumn{2}{|c|}{ Variable } & 1 & 2 & 3 & 4 & 5 & 6 & 7 & 8 & 9 & 10 \\
\hline 1 & Age & - & & & & & & & & & \\
\hline 2 & Career length & $0.895^{* *}$ & - & & & & & & & & \\
\hline 3 & Education level & 0.022 & -0.013 & - & & & & & & & \\
\hline 4 & Shift work & -0.042 & 0.011 & $-0.123^{*}$ & - & & & & & & \\
\hline 5 & Use of PPE & $0.142^{*}$ & 0.107 & -0.042 & $0.141^{*}$ & - & & & & & \\
\hline 6 & Experience of corona & 0.057 & 0.029 & 0.024 & 0.025 & -0.101 & - & & & & \\
\hline 7 & Awareness on corona & -0.058 & $-0.131^{*}$ & $0.151^{*}$ & -0.003 & 0.060 & -0.067 & - & & & \\
\hline 8 & Attention to preventive measures & $-0.126^{*}$ & 0.108 & -0.014 & 0.038 & 0.079 & 0.104 & 0.095 & - & & \\
\hline 9 & Hypochondriasis & $0.196^{* *}$ & $0.232^{* *}$ & 0.054 & 0.042 & $0.183^{* *}$ & $0.146^{*}$ & $-0.152^{*}$ & $-0.136^{*}$ & - & \\
\hline 10 & Job stress & 0.097 & $0.129^{*}$ & 0.065 & 0.004 & 0.009 & $-0.228^{* *}$ & $-0.142^{*}$ & $-0.121^{*}$ & $0.406^{* *}$ & - \\
\hline
\end{tabular}

made questionnaire. Therefore, the scores of the variables of hypochondriasis and job stress can be calculated if the scores of the related variables are placed into the equations.

The results also show that the score of job stress can be predicted by the score of corona-induced hypochondriasis variable, whose relationship is presented in the following:

Job stress $=63.28+1.307 \mathrm{X} 1$

In this equation, $\mathrm{X} 1$ is the score of corona-induced hypochondriasis.

\section{Discussion}

The present study was aimed to determine the effect of the individual factors on hypochondriasis and job stress under the corona epidemic condition in a workplace. The data were collected using demographic, researcher-made, standard hypochondria, and job stress questionnaires. The workers of a company completed the questionnaires. Then, the data were analyzed in SPSS. In general, the results of the present study show that the score of hypochondriasis in different groups of variables of age, work experience, use of personal protective equipment, corona experience, and attention to preventive measures was significantly different. In this regard, people over the age of 30 years and with the work experience of more than 20 years had higher hypochondriasis scores. In explaining this finding, it can be argued that the risk of developing hypochondriasis disorder increases along with the increase of age because of the possibility of the increased depression, fear of disease, and death. Notably, in a study by Bravo et al, which was conducted on 106 old people in 2001, the results showed that depression plays a role in the incidence of hypochondriasis (25). However, according to a study by Jonathan et al, on 27 patients with hypochondriasis disorder, no significant relationship was observed between hypochondriasis and age (26). Also, in a study by Fallon et al (2012), no significant relationship was found between age and hypochondriasis disorder (27). Correspondingly, perhaps the reason for this discrepancy is the difference in the number of participants and the statistical population. In the present study, a significant relationship was observed among the hypochondriasis score and the variables of personal protective equipment use, corona experience, and attention to preventive measures. Accordingly, it was found that people with a low history of using PPE, with coronary experience, and with a low history of attention to preventive measures, had a higher hypochondriasis score. Therefore, it seems that due to the lack of vaccines and effective treatment against
Covid-19 disease, by implementing some preventive measures, including using a face mask; regular handwashing; preventing contact with the infected people and maintain a safe distance; and avoiding touching eyes, mouth, and nose with unwashed hands can prevent people from being infected by Covid-19, which subsequently reduces the rate of hypochondriasis disease (3). Based on the results of the present study, the score of hypochondriasis was not significantly different in variables of education level, work shift, and awareness about the corona disease. In line with the present study, in a study conducted by Jonathan, no significant relationship was observed between the level of education and hypochondriasis (26). Regarding the obtained results, it can be inferred that the level of education under during the Covid-19 epidemic does not have an effect on people's mental health. Based on the results of the present study, job stress scores were significantly different in personal protective equipment use, corona experience, and awareness on the corona disease. In this regard, people with a low record of using PPE, a corona disease experience, and a low level of knowledge on the corona disease had higher job stress scores. Also, the implementation of individual preventive measures, such as the use of face masks, continuous handwashing, and organizational measures, such as installing the proper ventilation and observance of social distance, will reduce psychiatric symptoms (11) and can lead to the absence of Covid-19 disease.

It is suggested that the necessary trainings be put on the agenda of the industries to be aware of the corona disease and take preventive measures. In this regard, the health belief model can be used. Also, according to this model, if people see themselves as sensitive to a situation and believe that they can reduce the complications by taking some actions and taking these actions are more beneficial than not doing it, they will engage in preventive behaviors (28). According to this research results, based on the existing high stress in people who have a low history of using PPE and due to the positive effect of using these devices, it is necessary to consider and implement encourage and punishment systems to use personal protective equipment correctly and completely. However, the score of this parameter in different groups of variables of age, work experience, level of education, work shift, and attention to preventive measures did not differ significantly. Contrary to the findings of the present study, in a study by Hosseinzadeh et al, which was conducted to determine the level of stress, anx- 
iety, and depression on 200 health workers during the epidemic of Covid-19, it was reported that there is a significant relationship between age and education with job stress. Thus, with increasing the age and education, the amount of stress reduces. Differences in the results of the above-mentioned study and the present study could be due to the dissimilarity of the statistical population, their workplace, and differences in the tools used (DASS Scale in the study by Hosseinzadeh et al) (7). It is also possible that some factors such as the experience modified the effect of age on job stress in the present study. In line with the present study, in a study by Alomar, no significant relationship was found between education degree and job stress (12). According to the regression model proposed in this study, job stress increases as hypochondriasis increases. Therefore, it is suggested that the necessary planning be done to implement measures for reducing the incidence of hypochondriasis among employees, such as appropriate trainings on the prevention and coping with the corona disease. It is also possible to increase the resilience rate of people as an effective approach, to deal with stressful situations and being safe from the danger of pathogenic disorders. Accordingly, resilience is a dynamic process leading to positive adaptation to bitter and unpleasant experiences in life. In other words, resilience leads to the adjustment of stress levels and disability under stressful conditions (29). According to a study by Shatté et al in 2017, a higher level of resilience had beneficial effects on workers' perceptions of stress and psychological response to it as well as in the face of work environments. Moreover, it was reported that, especially in those environments with hard work, workers have higher resilience levels, less absenteeism from work, and are more productive compared to other workers with lower resilience levels (30). It is suggested that objective methods be used in future studies to examine job stress and demographic factors that were not studied in this study, such as income level, smoking, and gender.

\section{Conclusion}

According to the results of the present study, several significant relationships were observed among hypochondriasis and variables of corona experience, age, history of use of personal protective equipment, and attention to preventive measures. In this regard, the highest correlation with this variable was related to work experience. Also, there were significant relationships between stress and the variables of corona experience, awareness about corona, and the use of PPE, among which the corona experience variable had the highest correlation. In addition, the results show that corona-induced hypochondriasis has a significant positive relationship with job stress. Despite the outbreak of the coronavirus disease, it is necessary that industries start working to prevent the economic recession. Regarding the importance of providing the physical and mental health of employees as the main assets of the industries, the implementation of measures to reduce stress and hypochondriasis of employees is helpful in tolerating these difficult conditions.

\section{Acknowledgement}

This research was funded by Ahvaz Jundishapur University of Medical Sciences, grand number IR.AJUMS.REC.1399.634

\section{Conflict of Interests}

The authors declare that they have no competing interests.

\section{References}

1.Gorbalenya AE, Baker SC, Baric R, Groot RJd, Drosten C, Gulyaeva AA, et al. Severe acute respiratory syndrome-related coronavirus: The species and its viruses-a statement of the Coronavirus Study Group. 2020 .

2.Lai CC, Shih TP, Ko WC, Tang HJ, Hsueh PR. Severe acute respiratory syndrome coronavirus 2 (SARS-CoV-2) and corona virus disease-2019 (COVID-19): the epidemic and the challenges. Int J Antimicrob Agents. 2020:105924.

3.Di Gennaro F, Pizzol D, Marotta C, Antunes M, Racalbuto V, Veronese $\mathrm{N}$, et al. Coronavirus diseases (COVID-19) current status and future perspectives: a narrative review. Int J Environ Res Public Health. 2020;17(8):2690.

4. Killgore WD, Taylor EC, Cloonan SA, Dailey NS. Psychological Resilience During the COVID-19 Lockdown. Psychiatry Res. 2020:113216.

5.Shahsavarani AM, Azad Marz Abadi E, Hakimi Kalkhoran M. Stress: Facts and theories through literature review. Int $J$ Med Rev. 2015;2(2):230-41.

6.Al-Saleh SA, Al-Madi EM, Al-Angari NS, Al-Shehri HA, Shukri MM. Survey of perceived stress-inducing problems among dental students, Saudi Arabia. Saudi Dent J. 2010;22(2):83-8.

7.Hosseinzadeh-Shanjani Z, Hajimiri K, Rostami B, Ramazani S, Dadashi M. Stress, Anxiety, and Depression Levels Among Healthcare Staff During the COVID-19 Epidemic. Basic Clin Neurosci. 2020;11(2):16370 .

8.Akporehe DA. The impact of environment on productivity in secondary schools. S Afr J Educ. 2011;1(1):116-22.

9.Ekienabor E. Impact of job stress on employees' productivity and commitment. Int J Bus Res. 2016;2(5):124-33.

10.Hoboubi N, Choobineh A, Ghanavati FK, Keshavarzi S, Hosseini AA. The impact of job stress and job satisfaction on workforce productivity in an Iranian petrochemical industry. Saf Health Work . 2017;8(1):6771.

11.Tan W, Hao F, McIntyre RS, Jiang L, Jiang X, Zhang L, et al. Is returning to work during the COVID-19 pandemic stressful? A study on immediate mental health status and psychoneuroimmunity prevention measures of Chinese workforce. Brain Behav Immun. 2020; vol(87):84-92.

12.A1-Omar BA. Sources of work-stress among hospital-staff at the Saudi MOH. Econ Adm. 2003;17(1).

13.Manshor AT, Fontaine R, Choy CS. Occupational stress among managers: a Malaysian survey. J Manag Psychol. 2003; vol(18):622-8.

14.Ofili A, Asuzu M, Isah E, Ogbeide O. Job satisfaction and psychological health of doctors at the University of Benin Teaching Hospital. Occup Med. 2004;54(6):400-3.

15.Edition F. Diagnostic and statistical manual of mental disorders. Am Psychiatric Assoc. 2013.

16.Sadock BJ, Sadock VA, Ruiz P. Comprehensive textbook of psychiatry: lippincott Williams \& wilkins Philadelphia, PA; 2000.

17.Pasah G. The prevalence of hypochondriasis and its relation to anxiety, depression and other personal characteristics of students. Knowledge Res Appl Psychol. 2005;25(3):1-20.

18.Fink P, Ørnbøl E, Toft T, Sparle KC, Frostholm L, Olesen F. A new, empirically established hypochondriasis diagnosis. Am J Psychiatry. 2004;161(9):1680-91.

19.Barsky AJ, Frank CB, Cleary PD, Wyshak G, Klerman GL. The relation between hypochondriasis and age. Am J Psychiatry. 1991;148:923-928.

20.Aghili SM, Arbabi M. The COVID-19 Pandemic and the Health Care Providers; What Does It Mean Psychologically? Adv J Emerg Med. 2020;4(2s).

21.Evans C. Understanding yourself: Signet; 1980. 
22.Khani H, Ghodsi H, Nezhadnik H, Teymouri S, Ghodsi A. Depression and its relationship with hypochondriasis in nurses in Neyshabur, Iran. Mil Caring Sci. 2016;3(1):34-40.

23. Osipow SH, Spokane AR. Occupational stress inventory-revised. Odessa, FL: Psychological. 1998:1-15.

24.Sharifian S, Aminian O, Kiyani M, Barouni S, Amiri F. The evaluation of the degree of occupational stress and factors influencing it in forensic physicians working in legal medicine organization in Tehran-autumn of 2005. Sci J Forensic Med. 2006;12(3):144-150.

25.Bravo IM, Silverman W. Anxiety sensitivity, anxiety, and depression in older patients and their relation to hypochondriacal concerns and medical illnesses. Aging Ment Health. 2001;5(4):349-57.

26.Abramowitz JS, Moore EL. An experimental analysis of hypochondriasis. Behav Res Ther 2007;45(3):413-24.

27.Fallon BA, Harper KM, Landa A, Pavlicova M, Schneier FR, Carson A, et al. Personality disorders in hypochondriasis: prevalence and comparison with two anxiety disorders. Psychosomatics. 2012;53(6):566-74.

28.Glanz K, Rimer BK, Viswanath K. Health behavior and health education: theory, research, and practice: John Wiley \& Sons; 2008.

29.Abolghasemi A, Varaniyab ST. Resilience and perceived stress: predictors of life satisfaction in the students of success and failure. Procedia Soc Behav Sci. 2010;5:748-52.

30.Shatté A, Perlman A, Smith B, Lynch WD. The positive effect of resilience on stress and business outcomes in difficult work environments. Int J Occup Environ Med. 2017;59(2):135. 